\title{
Operative treatment of typhoid perforation with peritoneal irrigation: a comparative study
}

\author{
O A BADEJO AND A O ARIGBABU
}

From the Department of Surgery, Anaesthesia and Intensive Care, Faculty of Health Sciences, University of Ife, Ilé-Ifé, Nigeria

SUMmaRY Two hundred and ten cases of typhoid enteritis were seen and treated in Ife, Nigeria, between 1972 and June 1979. A comparative analysis was made between those treated conservatively and surgically. A new and hitherto undescribed method of approach, peritoneal irrigation after surgery, was used in 180 patients. The results obtained have convinced us that all cases of typhoid must be promptly and adequately resuscitated, operated, drained, and irrigated.

Typhoid fever with enteritis and its complications form the major types of clinically known 'acute abdomen' in Nigeria. Perforation, one of the main features associated with this disease, has hitherto remained a deadly complication. Although this is said to occur in $30 \%$ of adults ${ }^{1,2,3}$, an increasing number of perforations occur in children as well, and, in our experience, the rate of perforation is even higher in adults. Most of these are ball-pen pointed and are easily missed on exploration. Operative management has been on the increase since Archampong's report ${ }^{4}$ and the success associated with our method of approach, as shown by this comparative study over a $6 \frac{1}{2}$ year period, has led to this report.

\section{Methods}

We studied 210 cases of typhoid from the Ife and Ijesha divisions of Oyo State seen and treated in Ife hospitals between 1972 and June 1979. Thirty of these cases were taken at random from old records. Their ages ranged from 0 to 65 years. The others were all the cases that have come into hospital since teaching and research began in Ife. There was no selection as to age group or sex. Most of the patients came from the farms in the suburban areas. The diagnosis of salmonella infection was based in all cases on abdominal symptoms, the stepwise fashion of persistent fever, constipation, diarrhoea, and raised Widal titre. The cases were considered on a comparative basis and the results obtained from peritoneal irrigation were compared with those with conservative treatment, as well as with those

Received for publication 15 August 1979 who had laparatomy alone without additional irrigation. All cases were reviewed for age and sex, clinical presentation, laboratory findings, and radiographic investigation as well as management. The various periods of hospitalisation and mortality with sex ratio were analysed, while consideration was given to possible complications arising in cases with peritoneal irrigation. Histological studies of the plaques removed at random from the ileum during surgery were also carried out.

\section{AGE AND SEX DISTRIBUTION}

Of the 210 patients reviewed, 23 were children in the age group 0 to 15 years; 13 of these were aged 0 to 10 years, with eight boys and five girls. The remaining 10 were aged 11 to 15 years, with 14 boys and nine girls. Of the adults, 65 were females, while 122 were males; their ages ranged from 16 to 65 years with a peak between 16 and 30 years (Table 1).

\section{CLINICAL PRESENTATION}

One hundred and twenty nine patients $(61.43 \%)$ were admitted to hospital with complaints of acute abdominal pain which had begun from seven days to two weeks before; it started just below the umbilicus

Table 1 Age and sex distribution

\begin{tabular}{|c|c|c|c|c|}
\hline \multirow{2}{*}{$\begin{array}{l}\text { Age } \\
(y r)\end{array}$} & \multicolumn{2}{|c|}{ Sex distribution } & \multicolumn{2}{|c|}{ Patients } \\
\hline & Male & Female & (no.) & $(\%)$ \\
\hline $0-10$ & 8 & 5 & 13 & 6.20 \\
\hline $11-20$ & 30 & 18 & 48 & 22.85 \\
\hline $21-30$ & 54 & 26 & 80 & 38.09 \\
\hline $31-40$ & 20 & 15 & 35 & 16.66 \\
\hline $41-50$ & 15 & 6 & 21 & 10.00 \\
\hline Over 50 & 9 & 4 & 13 & 6.20 \\
\hline Total & 136 & 74 & 210 & $100 \cdot 00$ \\
\hline
\end{tabular}


Table 2 Distribution of case severity with sex ratio

\begin{tabular}{|c|c|c|c|c|c|c|}
\hline \multirow{4}{*}{$\begin{array}{l}\text { Age group } \\
(y r)\end{array}$} & \multicolumn{6}{|c|}{ Type of case } \\
\hline & \multicolumn{3}{|c|}{ Mild typhoid } & \multicolumn{3}{|c|}{$\begin{array}{l}\text { Severe typhoid with } \\
\text { perforation, appendicitis }\end{array}$} \\
\hline & \multirow{2}{*}{$\begin{array}{l}\text { Patients } \\
\text { (no.) }\end{array}$} & \multicolumn{2}{|c|}{$\begin{array}{c}\text { Sex } \\
\text { distribution }\end{array}$} & \multirow{2}{*}{$\begin{array}{l}\text { Patients } \\
\text { (no.) }\end{array}$} & \multicolumn{2}{|c|}{$\begin{array}{l}\text { Sex } \\
\text { distribution }\end{array}$} \\
\hline & & $M$ & $F$ & & $M$ & $F$ \\
\hline 0.10 & 3 & 2 & 1 & 10 & 6 & 4 \\
\hline $11-20$ & 10 & 7 & 3 & 38 & 26 & 12 \\
\hline $21-30$ & 22 & 12 & 10 & 58 & 39 & 19 \\
\hline $31-40$ & 5 & 3 & 2 & 30 & 17 & 13 \\
\hline $41-50$ & 3 & 2 & 1 & 18 & 13 & 5 \\
\hline Over 50 & 2 & 2 & 0 & 11 & 7 & 4 \\
\hline \multirow[t]{2}{*}{ Total } & 45 & 28 & 17 & 165 & 108 & 57 \\
\hline & & \multicolumn{2}{|c|}{ Ratio } & & \multicolumn{2}{|c|}{ Ratio } \\
\hline$\%$ & $21 \cdot 42$ & \multicolumn{2}{|c|}{$1 \cdot 65: 1$} & 78.57 & \multicolumn{2}{|c|}{$1.90: 1$} \\
\hline
\end{tabular}

but later radiated downwards and laterally to cover the whole lower abdomen. They could neither stand nor walk, and were toxic, dehydrated, and wasted, with distended abdomens tympanic to percussion and sensitive to touch. These cases are referred to clinically as severe typhoid with perforation and acute appendicitis (Table 2). Fifty-one others were admitted with similar complaints ranging from one to seven days; they appeared to be less toxic and are referred to as cases of mild typhoid. These foimed $24.3 \%$ of the cases reviewed. All the patients had spells of diarrhoea, alternating with constipation, while fever, vomiting, and loss of appetite were found in 47 patients $(22.4 \%)$. Bowel sounds were completely absent in 43 cases $(23.88 \%)$ on admission, while all others (137 cases) initially had hypoactive sounds. Severe anaemia (PCV 20\% and below) accompanied with malnutrition was present in 21 patient $(11 \cdot 66 \%)$.

\section{LABORATORY INVESTIGATIONS}

Routine full blood count and blood examination of the stool were carried out in all 180 cases. These were followed by Widal reaction (100 cases), stool culture (30 cases), urine culture (five cases), blood culture (15 cases), and culture of peritoneal fluid

\section{Table 3 Laboratory findings}

\begin{tabular}{|c|c|c|c|}
\hline & \multirow[b]{2}{*}{ No. examined } & \multicolumn{2}{|c|}{$\begin{array}{l}\text { Positive } \\
\text { results }\end{array}$} \\
\hline & & (no.) & $(\%)$ \\
\hline Widal reaction alone & 1007 & 52 & $28 \cdot 88$ \\
\hline Stool culture alone & 30 & 8 & $4 \cdot 44$ \\
\hline Urine culture alone & $5 \succ 180$ & 2 & $1 \cdot 11$ \\
\hline Blood culture alone & 15 & 6 & $3 \cdot 33$ \\
\hline Peritoneal fluid culture alone & 30 & 9 & $5 \cdot 00$ \\
\hline Blood in stool & 180 & 180 & $100 \cdot 00$ \\
\hline $\begin{array}{l}\text { Leucocytosis of } 8300 / \mathrm{cm}^{3} \\
\text { and above }\end{array}$ & 180 & 166 & $92 \cdot 22$ \\
\hline $\begin{array}{l}\text { Leucopenia of } 3000 / \mathrm{cm}^{3} \\
\text { and below }\end{array}$ & 180 & 14 & $7 \cdot 77$ \\
\hline
\end{tabular}

(30 cases). Where a preceding test had proved positive for one investigation, the results of further tests are omitted to avoid the overlapping of positive results (Table 3 ).

\section{X-RAY INVESTIGATION}

This was carried out in 180 patients with distended abdomen where ileus and perforations were suspected.

\section{Management}

\section{CONSERVATIVE TREATMENT}

This method of treatment prevailed in Ife before the establishment of teaching hospitals, and principally involved chloramphenicol. The dosage ranged between $750 \mathrm{mg}$ and $2 \mathrm{~g}$ intravenously every six hours. Accurate records of the gradual reduction of the dose could not be obtained from records during this study (Table 4).

\section{SIMPLE LAPAROTOMY WITHOUT IRRIGATION} Laparotomy was performed in this group of patients (15 cases) and the perforation closed with a twolayer 4-0 silk suture after $2 \mathrm{~g}$ chloramphenicol had been instilled into the lumen of the gut, distally. This was followed by thorough toilet of the abdominal cavity with warm saline solution and wound closure in layers. Patients also received $750 \mathrm{mg}$ chloramphenicol intravenously six-hourly for two weeks, with a gradual reduction of the dosage.

\section{EXTENSIVE LAPAROTOMY WITH PERITONEAL IR RIGATION}

A total of 165 unselected, random cases in the age group 3 to 65 years was treated by this method. Perforations only were sutured in 110 cases, while in 55 patients who had multiple perforations resection and anastomosis were carried out. The lesions were $20-40 \mathrm{~cm}$ from the ileocaecal valve. Where the perforation was only the size of a ball-pen tip, an extension was made and the entire contents of the intestines milked out. This was followed by instillation of $2 \mathrm{~g}$ chloramphenicol into the lumen of the

Table 4 M.Inagement

\begin{tabular}{llll}
\hline \multicolumn{5}{c}{ No. of patients with: } & \\
\cline { 2 - 3 } $\begin{array}{l}\text { Age groups } \\
(\text { yr) }\end{array}$ & $\begin{array}{l}\text { Conservative } \\
\text { treatment }\end{array}$ & $\begin{array}{l}\text { Laparotomy } \\
\text { without } \\
\text { irrigation }\end{array}$ & $\begin{array}{l}\text { Laparotomy and } \\
\text { peritoneal } \\
\text { irrigation }\end{array}$ \\
\hline $0-10$ & 1 & 2 & 10 \\
$11-20$ & 6 & 3 & 38 \\
$21-30$ & 12 & 3 & 58 \\
$31-40$ & 5 & 2 & 30 \\
$41-50$ & 3 & 2 & 18 \\
Over 50 & 3 & 3 & 11 \\
Total & 30 & 15 & 165 \\
$\%$ & $14 \cdot 28$ & $7 \cdot 14$ & $78 \cdot 57$ \\
\hline
\end{tabular}


ileum. Appendicectomy was performed routinely. A thorough toilet of the abdominal cavity was carried out with warm saline solution in which $4 \mathrm{~g}$ chloramphenicol per litre of fluid was dissolved. A peritoneal irrigation with inlet in the right hypochondrium and outlet from the pouch of Douglas was performed. The solution used for irrigation was dextran into which $4 \mathrm{~g}$ chloramphenicol per litre was dissolved, together with one million international units of Trasylol. The rate of flow was 20 drops per minute after 1 litre of the solution had been initially instilled intra-abdominally. The outlet was closed primarily to allow the intestines to float within the instilled fluid. Irrigation was continued for five days simultaneously with the intravenous application of chloramphenicol, which was given six-hourly. The outlet was opened half-hourly for the first 24 hours, and then every two hours except when respiratory distress was noticed. A blocked nasogastric tube remained in situ for 48 to 72 hours. Blood was given at operation and on the first postoperative day, depending on PCV, which was checked regularly, and the general condition of the patient. The irrigation inlet was closed as soon as review of abdomen allowed for closure, usually on the fifth postoperative day, while the outlet remained open as long as the typical yellowish, and offensive fluid continued to flow out with sediments. The average period for the removal of the outlet drain was 10 days. Electrolyte imbalance was corrected with adequate substitution, while protein deficiency, mainly due to malnutrition, was compensated for by feeding with a high protein diet and casilan mixed with milk six-hourly as soon as the patient had a bowel motion. A full dosage of digoxin was given in all cases of cardiac failure (40 patients $19.05 \%$ ).

\section{Results}

\section{AGE AND SEX DISTRIBUTION}

There were 14 boys to nine girls in the age group 0 to 15 years, giving a ratio of $1 \cdot 5: 1$. The peak age group ranged between 21 years and 30 years with 80 patients, forming $36.2 \%$ of the entire series and with a male/female ratio of 2:1 (Tables 1 and 2).

\section{LABORATORY FINDINGS}

Examination for blood in the stool was positive in all the 180 cases examined, while Widal reaction with the highest titre of $1: 200$ as read after two hours at $37^{\circ} \mathrm{C}$ for $\mathrm{H}$-agglutination, and $1: 160$ as read for 0 -agglutination after 20 hours at $37^{\circ} \mathrm{C}$ was positive in 52 cases out of the 100 cases examined. There were eight positive stool cultures out of 30 , while urine and blood culture gave two and six positive cases respectively (Table 3 ). Culture of the aspirated peritoneal fluid was positive in nine cases. Leucocytosis of $8300 / \mathrm{cm}^{3}$ and above was recorded in 166 patients $(92 \cdot 22 \%)$, while leucopenia of $3000 / \mathrm{cm}^{3}$ and below was found in 14 cases $(7 \cdot 22 \%)$.

\section{HIST O LOG Y}

Histological study of the plaques removed from the ileum during surgery showed oedematous connective tissues with extensive lymphocytic, monocytic, and rare neutrophilic infiltration. Typical typhoid cells were found in 16 cases only, an average of $7 \cdot 62 \%$.

X-RAY INVESTIGATIONS

Of the 165 patients with perforations found at surgery, only 10 showed evidence of pneumoperitoneum in $x$-ray films. All other cases showed gas-laden and grossly dilated intestinal loops with numerous fluid levels.

\section{LAPAROTOMY FINDINGS}

A total of 165 cases described as severe typhoid with perforation and acute appendicitis were found during surgery. One hundred and eight of these were males and 57 females, giving a male/female ratio of $1.90: 1$. Of these, 17 cases were children $(10 \cdot 30 \%)$ while 148 were adults. Typical yellowish fibrin plaques were found in all cases, while greenish, partly thick, partly diluted fluid was found in the abdominal cavity. There were worms (ascaris) found in 150 patients, some of which had escaped into the cavity through the perforations.

\section{Hospitalisation and recovery:}

Table 5 shows the period of hospitalisation and rate of recovery in various age groups. Whereas patients in the conservatively treated group remained in hospital for six to 26 weeks, those with simple laparotomy remained for four to 12 weeks, while those treated by laparotomy and peritoneal irrigation were discharged after three to seven weeks. The length of stay in hospital was thus reduced by twothirds. As a rule the age groups 16 to 30 years recovered fully in the second week of admission, while patients who were over 40 years old and who

Table 5 Average period of hospitalisation expressed in weeks

\begin{tabular}{|c|c|c|c|c|c|c|}
\hline \multirow[b]{2}{*}{$\begin{array}{l}\text { Age groups } \\
(y r)\end{array}$} & \multicolumn{2}{|c|}{$\begin{array}{l}\text { Conservative } \\
\text { methods }\end{array}$} & \multicolumn{2}{|c|}{$\begin{array}{l}\text { Laparotomy } \\
\text { alone }\end{array}$} & \multicolumn{2}{|c|}{$\begin{array}{l}\text { Laparotomy with } \\
\text { irrigation }\end{array}$} \\
\hline & $\begin{array}{l}\text { Mild } \\
\text { cases }\end{array}$ & $\begin{array}{l}\text { Severe } \\
\text { cases }\end{array}$ & $\begin{array}{l}\text { Mild } \\
\text { cases }\end{array}$ & $\begin{array}{l}\text { Severe } \\
\text { cases }\end{array}$ & $\begin{array}{l}\text { Mild } \\
\text { cases }\end{array}$ & $\begin{array}{l}\text { Severe } \\
\text { cases }\end{array}$ \\
\hline $0-10$ & 6 & 8 & 4 & 6 & 2 & 3 \\
\hline $10-20$ & 8 & 12 & 4 & 8 & 2 & 4 \\
\hline $21-30$ & 10 & 24 & 5 & 7 & 2 & 4 \\
\hline $31-40$ & 14 & 22 & $5 \frac{1}{2}$ & 10 & 3 & 5 \\
\hline $41-50$ & 17 & 20 & 6 & 10 & $3 \frac{1}{2}$ & 6 \\
\hline Over 50 & 18 & 26 & 7 & 12 & $3 \frac{1}{2}$ & 7 \\
\hline
\end{tabular}


Table 6 Mortality in various methods of treatment with sex ratio

\begin{tabular}{|c|c|c|c|c|c|c|c|c|c|c|c|c|}
\hline \multirow{3}{*}{$\begin{array}{l}\text { Age groups } \\
\text { (yr) }\end{array}$} & \multicolumn{3}{|c|}{ Conservative ( 30 cases $)$} & & \multicolumn{4}{|c|}{ Laparatomy alone (15 cases) } & \multicolumn{4}{|c|}{$\begin{array}{l}\text { Laparatomy and peritoneal } \\
\text { irrigation ( } 165 \text { cases) }\end{array}$} \\
\hline & \multicolumn{2}{|c|}{ Mild } & \multicolumn{2}{|c|}{ Severe } & \multicolumn{2}{|c|}{ Mild } & \multicolumn{2}{|c|}{ Severe } & \multicolumn{2}{|c|}{ Mild } & \multicolumn{2}{|c|}{ Severe } \\
\hline & $M$ & $F$ & $M$ & $F$ & $\bar{M}$ & $F$ & $\bar{M}$ & $F$ & $\bar{M}$ & $F$ & $M$ & $F$ \\
\hline $0-10$ & 0 & 0 & 1 & 0 & 0 & 0 & 1 & 0 & 0 & 0 & 2 & 1 \\
\hline $11-20$ & 1 & 1 & 1 & 1 & 0 & 0 & 0 & 0 & 0 & 0 & 0 & 0 \\
\hline $21-30$ & 1 & 1 & 2 & 1 & 0 & 0 & 1 & 0 & 0 & 0 & 0 & 0 \\
\hline $41-50$ & 0 & 0 & 1 & 2 & 0 & 0 & 0 & 1 & 0 & 0 & 0 & 1 \\
\hline Over 50 & 0 & 0 & 2 & 1 & 0 & 0 & 0 & 1 & 0 & 0 & 1 & 0 \\
\hline Total & 3 & 2 & 9 & 6 & 0 & 0 & 3 & 2 & 0 & 0 & 3 & 2 \\
\hline Overall mortality & \multicolumn{4}{|c|}{$20 / 30=66.6 \%$} & \multicolumn{4}{|c|}{$5 / 15=33 \cdot 3 \%$} & \multicolumn{4}{|c|}{$5 / 165=3.03 \%$} \\
\hline
\end{tabular}

came in with severe shock, anaemia, and malnutrition recovered very slowly after the fourth week.

\section{MORTALITY AND CAUSES}

Of the 30 cases treated conservatively 20 died $(66.6 \%), 12$ males and eight females, giving a ratio of $3: 2$. There were five deaths in the simple surgical group without irrigation, a mortality of $33 \%$, with male/female ratio of $3: 2$. There were five deaths also out of $165(3.03 \%)$ in the third group with peritoneal irrigation: male/female ratio, again $3: 2$. There were no deaths at all in the middle age groups, while the corresponding age group in those conservatively treated gave the best survival rate (Table 6).

The causes of death were septicaemia, including encephalitis, cardiac failure, renal failure, peritonitis, and septic shock. Two of the patients who died in group three were operated on under local anaesthesia while the other three were given no anaesthesia at all because of their advanced toxic condition.

\section{ANALYSIS OF COMPLICATIONS IN CASES \\ OF LAPAROTOMY AND PERITONEAL \\ IR RIGATION (165 cases)}

A total of 99 complications $(60.0 \%)$ was recorded. Fourteen patients had a breakdown of wound alone. Another 23 patients $(23.23 \%)$ had not only the above but also enterocutaneous fistulae; These were repaired surgically with success. Fifteen out of the 165 operated cases developed postoperative multiple perforations requiring surgery, while 16 others developed fistulae, diarrhoea, and metabolic acidosis. Electrolyte imbalance, mainly potassium deficiency, metabolic alkalosis, and vomiting were found in 14 cases, while controllable respiratory distress was recorded in 11 cases. Subcutaneous oedema with scrotal swelling arising from an intracutaneous hole in the irrigating set located in the right hypochondrium was noted in six cases (Table 7).
Table 7 Complications in 165 cases of peritoneal irrigation

\begin{tabular}{|c|c|c|}
\hline \multirow[b]{2}{*}{ Type of complications } & \multicolumn{2}{|c|}{ Patients } \\
\hline & (no.) & $(\%)$ \\
\hline Breakdown of wound alone & 14 & $14 \cdot 14$ \\
\hline $\begin{array}{l}\text { Breakdown of wound with the formation of } \\
\text { enterocutaneous fistulae } \\
\text { Postoperative multiple perforations }\end{array}$ & 23 & $23 \cdot 23$ \\
\hline requiring re-laparatomy & 15 & $15 \cdot 15$ \\
\hline $\begin{array}{l}\text { Respiratory distress due to rise of diaphragm } \\
\text { Metabolic acidosis, diarrhoea (bloody) }\end{array}$ & 11 & $11 \cdot 11$ \\
\hline with fistulae & 16 & $16 \cdot 16$ \\
\hline $\begin{array}{l}\text { Subcutaneus oedema with scrotal swelling } \\
\text { arising from intracutaneous hole in irrigating }\end{array}$ & & \\
\hline $\begin{array}{l}\text { set } \\
\text { Electrolyte deficiency }\left(\mathrm{k}^{+}\right) \text {metabolic }\end{array}$ & 6 & $6 \cdot 10$ \\
\hline alkalosis and vomiting & 14 & $14 \cdot 14$ \\
\hline $\begin{array}{l}\text { Total } \\
\text { Percentage of complications }=60.00 \%\end{array}$ & 99 & $100 \cdot 03$ \\
\hline
\end{tabular}

\section{Discussion}

Several reports about the management of typhoid enteritis in the tropics have been published.1, 2, 4-6 Their findings of a preponderance of cases in the middle age group agree with ours. The finding of male predominance in this series also agrees with reports from Patel ${ }^{7}$ and Mathur and Sharma. ${ }^{8}$ The clinical features here are the same as those noted earlier by Osler ${ }^{9}, \mathrm{Li}^{10}$, Dickson and $\mathrm{Cole}^{11}, \mathrm{Kaul}^{1}$, and Ogunbiyi and his colleagues. ${ }^{2}$ However, Kaul in 1975 argued that the leucocyte count was less valuable, as this was increased in peritonitis and decreased in typhoid, and should be intermediate in perforation. We have found that severe perforation with leucocytosis was predominant in $92 \%$, while $7 \cdot 7 \%$ of cases with leucopenia were actually perforated (Table 3 ). We found no intermediate cases as suggested by Kaul.

We again agree with Kaul and Ogunbiyi and his colleagues that radiographic evidence of perforation is highly unreliable, as only $6.06 \%$ of our cases here showed pneumoperitoneum.

In all these series, the mortality rate has been 
found to be as high as $100 \%{ }^{1}$ The aggressive approach, advocated by Archampong ${ }^{4}$ and reemphacised by Kaul ${ }^{1}$ and Ogunbiyi and his colleagues $^{6}$, with simple drainage after laparotomy, reduced mortality to $50 \%$ in selected cases and $22 \%$ in children alone. The trend (in treatment) has been moving towards surgical management.

We have reported on 180 cases managed surgically out of 210 cases. Perforations were found in 165 patients. As far as we know, this is the highest figure ever reported, yet the mortality rate of $3.03 \%$ with male/female ratio of $3: 2$ and perforation male/female ratio of 1.90:1 is very significant. Of the 17 reported severe perforations in children, three died, giving a mortality rate of $17 \cdot 6 \%$ a figure less than that reported by Kaul. ${ }^{1}$

We adopted a method of operation similar to that of $\mathrm{Kaul}^{1}$ with the removal of all toxic intestinal contents, injected chloramphenicol distally into areas which could not be expressed by milking, and introduced, in addition, irrigation of the abdominal cavity to remove toxins, faecal matter, and other intestinal contents spilled into the peritoneal cavity or absorbed from the paralysed intestines before, during, or after the operation. We have also introduced irrigating with dextran mixed with Trasylol, a solution which we have found to prevent adhesions and conclusively confirmed in all our series of relaparotomies.

Analysis of the period of hospitalisation shows that, while simple laparotomy reduced the length of stay by about half, additional irrigation brought it down to less than a third of the stay of the conservatively treated patients (Table 5). Mortality figures in relation to treatment showed that less than $5 \%$ of the cases with peritoneal irrigation died. These results are the best, so far, in all the series reported and speak for the use of this aggressive method of approach.

An incidence of perforation of $78.57 \%$ has been described (Table 2). This is higher than that of Archampong ${ }^{4}(17.9 \%)$, Ogunbiyi and his colleagues ${ }^{6}$ $(17.8 \%)$, and more than double that of Olurin et al. ${ }^{2}$ $(33.6 \%)$ and confirms that the more cases reviewed and laparotomies performed, the higher the number of perforations which can be discovered.

We contend, in opposition to Huckstep ${ }^{3}$ and in agreement with Archampong ${ }^{4}$, Olurin et $a^{2}{ }^{2}$, Mulligan ${ }^{12}$, Kaul, ${ }^{1}$ and Ogunbiyi et al. ${ }^{6}$, that operative management is the safest method of treating typhoid enteritis. In addition, we also advance the view that peritoneal irrigation with prescribed ingredients and method is the only way to minimise intraperitoneal abscess, sepsis, intoxication, adhesion, secondary obstruction, mortality, and possibly incisional hernia after wound infection. A policy of active, adequate resuscitation, should, however, in our opinion be regarded as essential preoperatively and should be continued similarly postoperatively. Blood transfusion should also be advised in cases where bloody stool is persistently noticed. There is no reason why thousands of lives should not be saved by the simple method prescribed above, in the knowledge that the occurrence of typhoid enteritis in this part of the world is high indeed.

\section{References}

${ }^{1}$ Kaul BK. Operative management of typhoid perforation in children. Int Surg 1975;60:407-10.

${ }^{2}$ Olurin EO, Ajayi OO, Bohrer SP. Typhoid perforations. J R Coll Surg Ed 1972;17:353-63.

${ }^{3}$ Huckstep RL. Typhoid fever and salmonella infections. Edinburgh: E \& S Livingstone, 1962:217.

${ }^{4}$ Archampong EO. Operative treatment of typhoid perforation of the bowel. Br Med J 1969;3:273-6.

${ }^{5}$ Badoe EA. Typhoid perforation of the ileum in Korle Bu Hospital, Accra. Ghana Med J 1966;5:83-7.

${ }^{6}$ Ogunbiyi TAJ, Onabowale BO. Typhoid enteritis in Lagos, Nireria. Nigerian Med J 1976;6:505-11.

'Patel JC, Banker DD, Modi CJ. Typhoid fever. Indian Med Gaz 1954;89:400-6.

${ }^{8}$ Mathur GM, Sharma R. A study of typhoid fever in Jaipur, India Trop Geog Med 1971;23:329-34.

${ }^{9}$ Osler $\mathrm{W}$. The principles and practice of medicine. 8th ed. New York: D. Appleton, 1907.

${ }^{10} \mathrm{Li}$ FWP. Surgical treatment of typhoid perforation of the intestine. Brit J Surg 1963;50:976-9.

${ }^{11}$ Dickson JAS, Cole GJ. Perforations of the terminal ileum: a review of 38 cases. Br J Surg 1964;51:893-7.

${ }^{12}$ Mulligan TO. Treatment of typhoid perforation of the ileum. J Roy Coll Surg Ed 1972;17:364-8. 